\title{
PERSONALIDADE E PESSOA NO INTERIOR DA CONCEPÇÃO PEIRCIANA DE SER HUMANO
}

Rodrigo Vieira de Almeida

Doutor em Filosofia pela Pontifícia Universidade Católica de São Paulo (2016), área de concentração: Lógica e Epistemologia. Defendeu a tese sob o título: O conceito de imortalidade do homem na filosofia de Charles Sanders Peirce. Mestre em Filosofia pela Faculdade de São Bento (2011), área de concentração: Semiótica e Filosofia da Linguagem. Graduado em Letras, licenciatura plena, pela Faculdades Integradas Tibiriça (2005). E-mail: rodrigo.sandes.almeida@gmail.com

\section{RESUMO}

O presente artigo pretende tecer algumas considerações acerca de uma importante distinção operada por Peirce no interior da sua abordagem sinequista do ser humano, a saber, a distinção entre os conceitos de personalidade e pessoa. A definição peirciana da personalidade como consistindo em um tipo de coordenação ou conexão entre ideias (Cf. W 8.154) será analisada, levando em consideração a sua unidade e o fundamento ontológico que a justifica. A partir dessa análise, procurar-se-á explicitar, no espaço aqui disponível, porque apenas o fenômeno da personalidade, mesmo em sua persistência enquanto feixe de hábitos, não é suficiente para também explicar como alguém permanece sendo a mesma pessoa durante qualquer duração, independentemente das modificações que venha a sofrer. Surge, assim, a necessidade de se abordar como se dá a unidade da pessoa, como algo distinto da unidade da personalidade. Revelar-se-á que o conceito de pessoa, em Peirce, exige a realidade de uma unidade sucessiva de estados de consciência, que costuma ser expressa como "eu". Qual a natureza dessa unidade e como ela também se encontra devidamente assentada na ontologia realista/idealista de Peirce é o que, enfim, buscaremos clarificar.

PALAVRAS-CHAVE: Charles Sanders Peirce. Personalidade. Pessoa. Pragmatismo. Realismo. Idealismo Objetivo.

\section{PERSONALITY AND PERSON IN THE PEIRCEAN CONCEPT OF MAN}

\begin{abstract}
The present paper aims to make some considerations about an important distinction made by Peirce within his synechist approach to the human being, that is, the distinction between the concepts of personality and person. The
\end{abstract}


Peircean definition of personality as consisting of a kind of coordination or connection between ideas (cf. W 8.154) will be analyzed, taking into account its unity and the ontological foundation that justifies it. From this analysis, we will seek to make explicit, in the space available here, why the personality phenomenon alone, even in its persistence as a bundle of habits, is not enough to explain how one remains the same person during any duration, irrespective of the modifications it may suffer. There arises, therefore, the need to approach the unity of the personas something distinct from the unity of personality. It will be revealed that the concept of person in Peirce requires the reality of a successive unity of states of consciousness, which is usually expressed as "I". What the nature of this unity is and how properly it is also based on Peirce's realistic / idealist ontology is what, finally, we will seek to clarify.

KEYWORDS: Sanders Peirce. Personality. Person. Pragmatism. Realism. Objective Idealism.

\section{INTRODUÇÃO}

Pode-se dizer que um dos temas mais marcantes e heurísticos que podem ser extraídos da filosofia peirciana é a sua concepção de ser humano, desafiadoramente contrária às abordagens subjetivistas, dualistas e nominalistas do tema que tanto marcaram, e porque não dizer, ainda marcam, a história da filosofia em geral.

O presente texto pretende abordar uma importante, e muitas vezes negligenciada, distinção operada por Peirce no interior da sua abordagem sinequista do ser humano, a saber, a distinção entre os conceitos de personalidade e pessoa e, paralelamente, mostrar porque essa distinção não se resolve meramente predicando a primeira como geral e a segunda como particular, sob a égide do problema do estatuto do individual no autor.

Para realizar esse propósito, na primeira parte do texto analisaremos a definição peirciana da personalidade como um tipo de coordenação ou conexão entre ideias (Cf. W 8.154) a partir do fundamento ontológico que justifica a sua unidade e realidade. Assim, a presença das três categorias peircianas, primeiridade, segundidade e terceiridade, tomadas como modos de ser da realidade, sob a ótica de sua metafísica científica, permitirá uma compreensão mais completa da unidade da personalidade enquanto feixe de hábitos coordenados de maneira teleológica e desenvolvimentista, tal como preconizada pelo autor.

De outro lado, na segunda parte do texto, procuraremos explicitar porque apenas o fenômeno da personalidade, mesmo em sua persistência enquanto feixe de hábitos, não é suficiente para também explicar como alguém permanece sendo a mesma pessoa durante Complexitas - Rev. Fil. Tem., Belém, v. 5, n. 1, p. 56-66, jan./dec. 2020 - ISSN: 2525-4154 
qualquer duração, independentemente das modificações que venha a sofrer. A partir dessas reflexões, a necessidade de distinguir de maneira mais apurada a unidade da pessoa e a unidade da personalidade, ambas profundamente arraigadas na ontologia realista/idealista desenvolvida por Peirce no interior de sua filosofia, aparece de maneira contundente.

Essa distinção acabará por revelar, em um movimento conclusivo do artigo, que o conceito de pessoa peirciano implica na existência de uma unidade sucessiva de estados de consciência, que consiste exatamente naquilo que costumamos exprimir como sendo o "eu". Devido à essa característica, afeita em última instância a um contínuo, tal unidade não pode ser reduzida apenas ao seu componente individual, ou seja, à mera segundidade.

\section{O CONCEITO DE PERSONALIDADE}

Em um de seus textos mais importantes, A Lei da Mente ${ }^{1}$, Peirce definiu a personalidade como um tipo de coordenação ou conexão de ideias² ${ }^{2}$ Tal definição, fosse tomada de maneira isolada, pareceria mais uma afirmação obscura do que uma tentativa de esclarecer algum objeto de inquirição. Talvez por isso, Peirce buscou qualificá-la imediatamente:

[...] de acordo com o princípio que estamos rastreando, uma conexão entre ideias é ela mesma uma ideia geral, e uma ideia geral é um sentimento vivo.É evidente que demos pelo menos um passo apreciável na direção do entendimento da personalidade. (W 8.154)

Sendo a personalidade um tipo de ideia geral, ela deve, segundo Peirce, conter todas as três características de uma ideia geral, a saber: 1) deve ser um sentimento vivo; 2) deve ser capaz de se fundir com outras ideias, e, logo, com outras personalidades e 3) deve ter a capacidade de insistir, de ser um hábito. Sendo um fenômeno que tipifica um contínuo peirciano, a personalidade deve também ser capaz de infinita potencialidade e, portanto,

Essa personalidade, como qualquer ideia geral, não é uma coisa a ser apreendida em um instante. Ela deve ser vivida no tempo; nenhum tempo finito pode abraçá-la em sua plenitude. Ainda assim, em cada intervalo infinitesimal, ela está presente e viva, embora especialmente colorida pelo sentimento imediato daquele momento. (W 8.154)

Em cada instante, toda a série anterior está nela contida e toda a série posterior presente

\footnotetext{
${ }^{1} \mathrm{~W} 8.135-157$.

${ }^{2}$ Cf. W 8.154.
}

Complexitas - Rev. Fil. Tem., Belém, v. 5, n. 1, p. 56-66, jan./dec. 2020 - ISSN: 2525-4154 
virtualmente, assim, "aprendida em um momento, a personalidade é a autoconsciência imediata"3. Não obstante, considerando o passado, a personalidade é a série infinita anterior ao momento presente que a determina infinitesimamente e por isso configura matéria de cognição e de influência tanto para o momento presente quanto para o futuro. Considerando o futuro, a personalidade consiste nos hábitos a que está sujeita não de maneira absoluta, o que lhe dá a oportunidade de adquirir novos contornos, de mudar e crescer.

$\mathrm{Na}$ verdade, a referência ao futuro, ou seja, ao fato de a coordenação perdurar de uma certa maneira, expandindo em crescimento, mas persistindo vetorialmente enquanto cresce e adquirindo maiores contornos ao se associar com outras ideias seguindo a lei da mente, consiste em uma das características mais marcantes da personalidade. Mas isso revela ainda mais:

A palavra "coordenação" [...] sugere uma harmonia teleológica de ideias, e no caso da personalidade, essa teleologia é mais do que a mera perseguição propositada de um fim predeterminado; ela é uma teleologia desenvolvimentista. Isso é um caráter pessoal. Uma ideia geral, viva e consciente agora, já é determinante de atos no futuro em uma medida que não está consciente agora. (W 8.155)

Hábitos coordenados de uma maneira teleológica e desenvolvimentista formam uma personalidade ${ }^{4}$. Os fins de uma personalidade, presentes em toda a sua série infinita, prenhe de possibilidades, só podem ser conhecidos por meio das condutas à que dão luz, tal como qualquer hábito, segundo o pragmatismo do autor 5 .

No entanto, é crucial compreender que, de modo algum, os fins que os hábitos coordenados em uma personalidade perseguem devem ser finais em um sentido determinista, e, exatamente por isso, toda personalidade é um fenômeno sempre aberto: "o mero ato de carregar propósitos predeterminados é mecânico6". O que significa que ninguém é capaz de ter consciência completa de seus próprios fins e, por isso, uma personalidade pode, em seu processo de crescimento, encontrar espaço para a autocorreção, para o aprendizado e para a mudança de conduta.

Stanley Harrison, em sua pioneira tese de doutorado ${ }^{7}$, escrita em 1971, inteiramente

\footnotetext{
${ }^{3} \mathrm{~W} 8.155$.

${ }^{4}$ Consultar, (COLAPIETRO, 1989)

5 "Pragmatismo e personalidade são mais ou menos da mesma natureza." (CP 5.16). Para detalhes acerca do pragmatismo peirciano, consultar, (IBRI, 2015, capítulo 6).

${ }^{6} \mathrm{~W} 8.155$.

7 (HARRISON, 1971).

Complexitas - Rev. Fil. Tem., Belém, v. 5, n. 1 , p. 56-66, jan./dec. 2020 - ISSN: 2525-4154
} 
dedicada a desenvolver uma teoria peirciana da pessoa, foi o primeiro a mostrar que há uma profunda ontologia por detrás da concepção de ser humano de Peirce. Essa ontologia é o resultado da ideia de que, considerando a unidade da personalidade, sentimentos, ações e pensamentos são associados, respectivamente, às categorias de primeiridade, segundidade e terceiridade em seu viés metafísico, ou seja, às formas de ser reais que governam os fenômenos mentais, à luz do idealismo objetivo do autor ${ }^{8}$.

Assim, pode-se dizer que a unidade da personalidade considerada em sua imediaticidade consiste na unidade da personalidade como um sentimento, ou seja, na personalidade em seu aspecto de primeiridade, e é tipificada pelo conceito de quale-consciência enquanto unidade da consciência ${ }^{9}$.

Quale-consciência é uma consciência que é, em sua unidade, uma qualidade:

A "quale-consciência" não está circunscrita a sensações simples. Há um "quale" peculiar à cor roxa, embora ela seja a mistura do vermelho e do azul. Há um "quale" distinto em cada combinação de sensações, desde que seja realmente sintetizado, um "quale" distinto para cada dia e cada semana, um "quale" particular para toda a minha consciência pessoal. (CP 6.223)

A personalidade em seu aspecto de segundidade pode ser descrita como o estado de consciência que envolve algum tipo de dualidade. Peirce tomava o conceito de sensação como o caso tipificador desse tipo de consciência. Isso porque a sensação, segundo Peirce, "contém dois tipos de consciência radicalmente diferentes, uma é o sentimento e a outra é a consciência de ser compelida a sentir sob uma certa ocasião particular ${ }^{10}$."

Uma variedade desse tipo de consciência dual é a consciência da vontade, ou seja, a consciência que temos ao exercer uma força em alguma coisa fora da consciência, mas que, de certa maneira, segundo Peirce, é inseparável da consciência de sofrer o efeito da própria força exercida, sendo, por isso mesmo, dual ${ }^{11}$. No entanto, deve notar o leitor que, embora esse tipo de consciência exista na personalidade, ela, tomada em si não é uma consciência unitária. Ela é dual, contendo um elemento unitário que é a sua parte de sentimento (primeiridade dentro da segundidade).

\footnotetext{
${ }^{8}$ Para uma análise detalhada do idealismo objetivo peirciano, ver (IBRI, 2015, capítulo 4). Ver também (IBRI, 2000), (IBRI, 2001) e (IBRI, 2014).

${ }^{9}$ Cf. (HARRISON, 203-204).

${ }^{10} \mathrm{CP} 7.543$.

${ }^{11}$ Cf. CP 7.543.
} 
Por isso, não podemos falar de unidade da personalidade em termos de segundidade, mas sim apenas de um aspecto da personalidade que envolve a consciência de dualidade, mas, sem a qual, a própria noção de unidade da personalidade ficaria incompleta. A unidade da personalidade enquanto terceiridade, por outro lado, envolve a própria definição da lei da mente do autor, a saber: "[as] ideias tendem a se espalhar continuamente e a afetar determinadas outras que estão para com elas em uma relação peculiar de 'afetabilidade"” (W 8.136).

Isso porque a personalidade, na medida direta em que envolve o conceito de hábito, consiste exatamente na tendência que os sentimentos, ações e pensamentos têm, enquanto ideias, de se espalhar e adquirir generalidade, bem como certa coordenação. $O$ tipo de consciência envolvido em um hábito demonstra a ideia peirciana de que uma mediação real é operante no fenômeno da personalidade, uma mediação real que possui o poder de unificar o que antes estava desconexo em um fluxo contínuo coordenado teleologicamente.

Uma personalidade é, justamente, o feixe de hábitos, sempre aberto e nunca esgotado em nenhum intervalo finito, que torna efetivo ou potencialmente efetivo todo esse movimento coordenado de maneira teleológica de modo a abarcar tanto a finalidade em evolução como as possibilidades de aprendizado, crescimento e mudança de hábitos que, junto com o próprio cosmos, possuem a missão inerente às suas próprias naturezas de se tornarem cada vez mais razoáveis ${ }^{12}$.

\section{O CONCEITO DE PESSOA}

No artigo A Essência Vítrea do Homem ${ }^{13}$, Peirce mostra como um ser humano configura, de uma maneira bem específica, e ligeiramente diferente do conceito de personalidade, uma pessoa:

A consciência de uma ideia geral possui uma certa "unidade do ego" que é idêntica quando passa de uma mente à outra. É, portanto, bastante análoga a uma pessoa; e, de fato, uma pessoa é somente um tipo particular de ideia geral. (W 8.182)

Harrison foi também o primeiro a apontar a distinção que há, no interior da filosofia peirciana, entre os conceitos de personalidade e pessoa ${ }^{14}$. Essa diferença não se dá meramente

\footnotetext{
${ }^{12}$ Para mais detalhes acerca do conceito de personalidade em Peirce, consultar (ALMEIDA, 2016).

${ }^{13} \mathrm{~W} 8.165-183$.

${ }^{14}$ Cf. (HARRISON, 1971).
} 
como uma distinção entre o geral e o particular. Ou seja, não se trata de predicar a personalidade como geral e a pessoa como particular, aparecendo, assim, o problema do estatuto do indivíduo em Peirce ${ }^{15}$.

Há algo um pouco mais complexo nessa distinção, que merece ser analisado. $\mathrm{O}$ fenômeno da personalidade, mesmo em sua perduração, ou seja, em sua persistência enquanto feixe de hábitos, não explica como alguém permanece sendo a mesma pessoa durante qualquer duração, independentemente das modificações que venha a sofrer. Em outros termos, a unidade da personalidade, que possui a unidade de uma ideia geral não explica a unidade da pessoa, que implica, além da unidade de uma ideia geral, uma unidade sucessiva de estados de consciência, que costuma ser expressa como "eu"16.

Como explicar, então, a unidade da pessoa no interior da filosofia peirciana? O que seria a unidade de um sujeito que permanece sendo o mesmo, conforme mostram as experiências fenomênicas de auto asserção? Nos textos da série cognitiva (1868-1869) ${ }^{17}$, Peirce afirmou que não podemos ter um conhecimento intuitivo da nossa própria autoconsciência e que também não temos o poder de conhecer a nós mesmos por meio de uma mera instrospecção.

Ao contrário, o nosso conhecimento do mundo interno é derivado do nosso conhecimento dos fatos externos. Peirce parece manter essa mesma posição em seus escritos mais maduros. Harrison confirma isso de maneira contundente ao exibir como Peirce procura pensar a pura experiência do "eu" e acaba por concluir que tal experiência é a forma mais degenerada de terceiridade ${ }^{18}$ :

A forma mais degenerada de Terceiridade é quando concebemos uma mera Qualidade de Sentimento, ou Primeiridade, representando a si mesma, para si mesma, como Representação. Isto, por exemplo, seria a Pura Autoconsciência, que pode ser grosseiramente descrita como um mero sentimento que possui um instinto obscuro de um germe do pensamento. (CP 5.71)

A experiência do puro "eu" é, assim, uma experiência de uma qualidade de sentimento atrelada a um símbolo vivo que, em um dado momento, representa, enquanto sentimento, a si mesmo como uma representação. Desse modo, parece que a experiência do "eu”, permanece

${ }^{15}$ Cf. (HARRISON, 1971). Ver também, (MUIO, 1984).

${ }^{16} \mathrm{Cf}$. (HARRISON, 1971, p. 218-219).

${ }^{17} \mathrm{~W} 2.193-272$

${ }^{18}$ Cf. (HARRISON, 1971, p. 220).

Complexitas - Rev. Fil. Tem., Belém, v. 5, n. 1 , p. 56-66, jan./dec. 2020 - ISSN: 2525-4154 
constante pelos feixes de hábitos que constituem a personalidade, configura uma espécie de unidade na série contínua de um fenômeno sob a lei da mente, que adquiriu uma certa coordenação. O puro "eu” é, assim, em sua unidade, o ponto de partida e condição de possibilidade da auto asserção.

Mas, sendo a auto asserção do puro "eu" constante, algo a mais está presente no processo. Para explicar isso com mais acuidade, Peirce se valeu de uma interessante metáfora, que convém citar na íntegra:

Imagine que sobre o solo de um país, com uma única linha fronteiriça [...] há um mapa desse mesmo país. Este mapa pode alterar as províncias diferentes deste país em qualquer proporção. Mas, eu suponho que ele representa cada parte do país que possui uma única fronteira, por uma parte do mapa que possui uma única fronteira; que cada parte é representada como demarcada por tais partes como ela verdadeiramente é demarcada; que cada ponto do país é representado por um único ponto no mapa e que cada ponto no mapa representa um único ponto no país. Suponhamos, além disto, que esse mapa é infinitamente preciso em sua representação de modo que não haja qualquer partícula em qualquer grão de areia no país que não tenha sido representada no mapa se tivéssemos de examiná-lo por meio de um poder magnificentemente alto de ampliação. Já que tudo sobre o solo do país é mostrado no mapa, e já que o mapa jaz no solo do país, o mapa em si será retratado no mapa, e nesse mapa do mapa tudo o que há no solo deste país pode ser discernido, incluindo o mapa em si com o mapa do mapa em sua fronteira. Assim, haverá no mapa o mapa do mapa, e nele, um mapa do mapa do mapa, e assim por diante ad infinitum. Cada um desses mapas estando no interior de seus precedentes na série, haverá um ponto contido em todos eles, e este será o mapa de si mesmo. Cada mapa que direta ou indiretamente representa o país é em si mapeado no próximo; ou seja, no próximo, ele será representado como um mapa do país. Em outras palavras, cada mapa é interpretado como tal no posterior. Podemos dizer, portanto, que cada um é a representação do país no mapa posterior; e aquele ponto que está em todos os mapas é em si mesmo a representação de nada além dele mesmo e para nada além dele mesmo. É, portanto, a analogia precisa da pura autoconsciência. (CP 5.71)

A partir dessa metáfora, fica claro que a tentativa de tornar cognitiva a autoconsciência funcionaria exatamente como a representação do mapa contínuo descrito por Peirce. A série contínua de pontos que representa os mapas infinitamente implica em um tipo de unidade, mas uma unidade que só possui sentido representativo na sequência representativa. Obviamente, a sequência representativa é a representação de um mapa no próximo mapa, infinitamente. Nunca havendo término para essa série, só se pode dizer que ocorre uma representação de uma maneira insuficiente. 
Do mesmo modo, o ponto que pertence a todas as representações feitas durante o fluxo temporal, o "eu", é, quando tomado em si, insuficiente enquanto representação, mas, no entanto, é uma representação, uma representação perpétua de si mesmo e para nada além de si mesmo. Ao encerrar a metáfora do mapa, Peirce procura esclarecer ainda mais essa complexa afirmação:

Como tal, ela [A autoconsciência] é autossuficiente. Ela é poupada de ser insuficiente, ou seja, de ser nenhuma representação, justamente pela circunstância de que ela não é totalmente suficiente, ou seja, não é uma completa representação, mas somente um ponto sobre um mapa contínuo. (CP 5.71)

Portanto, tomado em si mesmo, esse "eu" funciona como um índice, apontando para um existente, no caso de um ser humano, uma pessoa individual. Mas, por outro lado, "[...] o "eu" também aponta para si mesmo como a totalidade do símbolo vivo que é, a saber, como o processo unificador da atividade sígnica cuja função e finalidade é representar" ${ }^{19}$.

Ou seja, curiosamente, exatamente por ser uma representação insuficiente dentro de um processo de representações, mais exatamente, uma representação insuficiente contínua, o "eu” funciona, para além da sua faceta indexical, como uma fonte de unidade da série contínua de representações que constituem um ser humano e sua personalidade, de modo que, por isso, o ser humano pode ser, e foi, definido por Peirce como um símbolo em perpétua evolução. Assim, o lugar próprio do indivíduo no interior da concepção peirciana de ser humano é, sugere-se, a de uma segundidade dentro de uma terceiridade ${ }^{20}$.

\section{CONSIDERAÇÕES FINAIS}

Diante dessas considerações, cabe enfim perguntar: em que, exatamente, a unidade da pessoa se diferencia da unidade da personalidade? A unidade da personalidade é continuidade de um feixe de hábitos coordenados, ao passo que a unidade da pessoa, por sua vez, é a unidade, de um lado, da contínua presença e consistência da pura autoconsciência do eu e, de outro, da contínua representação desse eu como unidade daquilo que contém: unidade de primeiridade e de terceiridade.

Enquanto representação, trata-se de uma unidade sempre inferida, posto que dependente da infinita série de representações. Enquanto puro “eu”, trata-se da condição de possibilidade e

\footnotetext{
${ }^{19}$ Cf. (HARRISON, 1971, p. 220).

${ }^{20}$ Para mais detalhes acerca do conceito de pessoa em Peirce, consultar (ALMEIDA, 2016).
} 
de evolução. Em outros termos, a unidade da pessoa é a condição de possibilidade de um processo de representação coordenado teleologicamente; a unidade da personalidade é o resultado do processo de unificação de uma dada coordenação teleológica de ideias.

Assim, é por meio da união dessas unidades, que configuram uma pessoa em sua realidade, que se pode dizer e experienciar o fato de que uma pessoa pode permanecer "a mesma" independentemente das modificações a que seja submetida durante um processo infinito de representação.

Isso nos permite concluir, enfim, que uma pessoa é também um contínuo, ou seja um geral cujos hábitos coordenados, ou, em outros termos, cuja personalidade possui a possibilidade de se tornar cada vez mais autoconsciente e objetivamente autocontrolada durante o processo de representação infinita ao qual os seres humanos, enquanto seres reais, estão sujeitos.

\section{NOTAS}

*O presente texto foi apresentado no $17^{\circ}$ Encontro Internacional de Pragmatismo, realizado entre os dias 06-09 de novembro de 2017, pelo Centro de Estudos de Pragmatismo da Pontifícia Universidade Católica de São Paulo (PUCSP) e está baseado em parte de um dos capítulos da minha tese de Doutorado, "O conceito de imortalidade do homem na filosofia de Charles Sanders Peirce", defendida publicamente em 2016.

\section{REFERÊNCIAS BIBLIOGRÁFICAS}

ALMEIDA, Rodrigo Vieira de. $O$ conceito de imortalidade do homem na filosofia de Charles Sanders Peirce. 2016. 264. Tese (Doutorado em Filosofia) - Programa de Estudos PósGraduados em Filosofia, Pontifícia Universidade Católica de São Paulo, São Paulo, 2016.

COLAPIETRO, Vincent Michael. Peirce's approach to the self a semiotic perspective on human subjectivity. New York : State University, 1989.(SUNY Series in Philosophy).

HARRISON, Stanley Martin. Man's glassy essence: an attempt to construct a theory of person based on the writings of Charles Sanders Peirce. Dissertation submitted in partial fulfillment of the requirements for the degree of Doctor of Philosophy in the
Department of Philosophy at Fordham University. New York: Fordham University, 1971. [Microfilmed by University Microfilms, A Xerox Company, Ann Arbor, Michigan].

IBRI, Ivo Assad. Kósmos Noetós: a arquitetura metafísica de Charles S. Peirce. São Paulo: Paulus, 2015.

(Ensaios Filosóficos). Sobre a identidade Ideal-Real na filosofia de Charles S. Peirce. In: Cognitio, São Paulo, ano 1, n. 1, p. 38-45, jul./dez. 2000.

Ser e aparecer na filosofia de Peirce: o estatuto da fenomenologia. In: Cognitio, São Paulo, ano 2, n. 2, p. 67-76, jan./jun. 2001.

. The continuity of life: on Peirce's objective idealism. In: Peirce and biosemiotics: a guess at the riddle 
of life. Edited by Vinicius Romanini; Eliseo Fernándes. New York ; London : Springer Dordrecht Heidelberg, 2014.

MUOIO, Patricia A. Peirce on the person. In: Transactions of the Charles S. Peirce Society, v. 20, n. 4, p. 169182, 1984.

PEIRCE, Charles S. Writings of Charles Sanders Peirce: a chronological edition. The Peirce Edition Project (Ed.). Bloomington: Indiana University Press, 1982-2010. 8 V. [citado $\mathrm{W}$ seguido pelo número do volume e do número da página]. . The collected papers of Charles Sanders Peirce. Eletronic Edition. Disponível em: . Acesso em: 29 maio 2011. [citado CP, seguido pelo número do volume e número do parágrafo].

ALMEIDA, R. V. Personalidade e Pessoa no Interior da Concepção Peirciana de Ser Humano. Complexitas - Rev. Fil. Tem. Belém, v. 5, n. 1, p. 56-66, jan./dec. 2020. Disponível em: http://www.periodicos.ufpa.br/index.php/complexitas/article/view/9537>. Acesso em: 01 de novembro de 2020. 